\title{
Isotopic Composition of Water Used in Triple-Point Cells
}

\author{
K. S. Gam • K. H. Kang • Y.-G. Kim • I. Yang
}

Published online: 2 April 2008

(C) The Author(s) 2008

\begin{abstract}
Isotopic analysis of the water used in KRISS triple point of water (TPW) cells was performed by three separate laboratories. The $\delta \mathrm{D}$ and $\delta^{18} \mathrm{O}$ isotopic composition of six ampoules, made from two TPW cells, were analyzed by isotope ratio mass spectrometers. The analysis data showed that $\delta \mathrm{D}$ and $\delta^{18} \mathrm{O}$ were $-62.17^{0} \%$ and $-9.41 \%$ for the KRISS-2002-Jan cell, and $-36.42 \%$ and $-4.08 \%$ for the KRISS2005-Jun cell. The temperature deviation of the triple point of water for these cells calculated from Kiyosawa's data and the definition of the TPW were $+45.07 \mu \mathrm{K}$ for the KRISS-2002-Jan cell, and $+25.49 \mu \mathrm{K}$ for the KRISS-2005-Jun cell. The KRISS TPW temperature was $+92 \mu \mathrm{K}$ higher than the CCT-K7 KCRV after correcting for the deviation of the isotopic composition from Vienna Standard Mean Ocean Water.
\end{abstract}

Keywords CCT key comparison 7 - Isotope ratio mass spectrometers ·

Isotopic composition · Vienna standard mean ocean water - Water triple point

\section{Introduction}

The triple point of water (TPW) is an important defining fixed point used to realize and establish the International Temperature Scale of 1990 (ITS-90) [1]. However, the TPW defined by ITS-90 was ambiguous in relation to the isotopic composition of the water. In the supplementary information for the ITS-90, the isotopic composition of water was briefly discussed. Variations in the isotopic content of naturally occurring water can give rise to measurable differences in the TPW temperature, and a TPW cell prepared from continental surface water can give lower values than those obtained

K. S. Gam $(\varangle) \cdot$ K. H. Kang · Y.-G. Kim · I. Yang

Division of Physical Metrology, Korea Research Institute of Standards and Science,

Daejeon 305-340, Republic of Korea

e-mail: ksgam@kriss.re.kr 
from a TPW cell made from ocean water [2]. Through the recent results of the Consultative Committee for Thermometry Key Comparison of TPW cells (CCT-K7), clear differences were observed in the realized national standards for the TPW among the participating laboratories [3]. A difference in the isotopic composition of the water was identified as one of the major sources that change the TPW temperature. Through the activities of the CCT task group constituted in 2004 [4], the definition of TPW was clarified. Based on the results of the CCT task group, the CCT recommended to the International Committee for Weights and Measures (CIPM) "that the definition of the kelvin refer to water of a specified isotopic composition" and "that this composition is the International Atomic Energy Agency reference material Vienna Standard Mean Ocean Water (V-SMOW)" at the 23rd CCT meeting [5,6].

Since 1990, KRISS has fabricated TPW cells and disseminated these cells to national calibration centers in Korea and several National Measurement Institutes (NMIs). In 1997, KRISS participated in the international comparison of TPW cells organized by the BIPM [7] to confirm the quality of KRISS TPW cells. In this comparison, the KRISS TPW temperature was within $0.11 \mathrm{mK}$ of the BIPM reference value. In 2003, KRISS participated in CCT-K7, and the triple point of the KRISS TPW cell was shown to be $47 \mu \mathrm{K}$ higher than the CCT-K7 KCRV.

In this work, we report the isotopic composition of the water in the KRISS TPW cells as analyzed by three separate laboratories following the recommendation of the CCT. The KRISS TPW temperature was corrected for the deviation of isotopic composition from V-SMOW. Also, the TPW temperature was compared with other NMIs participating in CCT-K7 that undertook an isotopic analysis.

\section{Measurements}

\subsection{Preparation of the TPW Cell and Water Ampoules}

Figure 1a shows the process of making the KRISS TPW cell, which is made of Pyrex glass. The TPW cells have a length of $40 \mathrm{~cm}$ and a diameter of $50 \mathrm{~mm}$, and the inner diameter of the thermometer well is $12 \mathrm{~mm}$. Before filling the cell with water, the Pyrex glass cell was cleaned thoroughly by soaking in a cleaning solution (50\% nitric acid $+50 \%$ water) overnight followed by steam cleaning for $2 \mathrm{~h}$. After that, high-purity filtered water was obtained by boiling water from a 2-1 capacity still. The resistivity of the filtered water, which was used to clean and fill the TPW cell, was higher than $14 \mathrm{M} \Omega \cdot \mathrm{cm}$. Water was condensed and filled to the desired height in the TPW cell, and then the mantle heater power was turned off. After that, the stopcock connection to the TPW cell was closed and the TPW cell was sealed carefully with an oxygen-LPG torch. In Fig. 1a, the Pyrex tube (position 1) was sealed first, and then the upper tube of the cell (position 2) was sealed. After that, the cell was set up vertically and the Pyrex tube (position 3) sealed. Then, the TPW cell and the sealed Pyrex tube, with the tube numbered from position 1 to position 3, were separated. Thereby, the sealed Pyrex (position 1 to position 3) tube contained the same water as the TPW cell.

The TPW cells were fabricated in two batches, the first batch in January 2002 and the second batch in June 2005. In CCT-K7, the KRISS local cell and transfer cells 

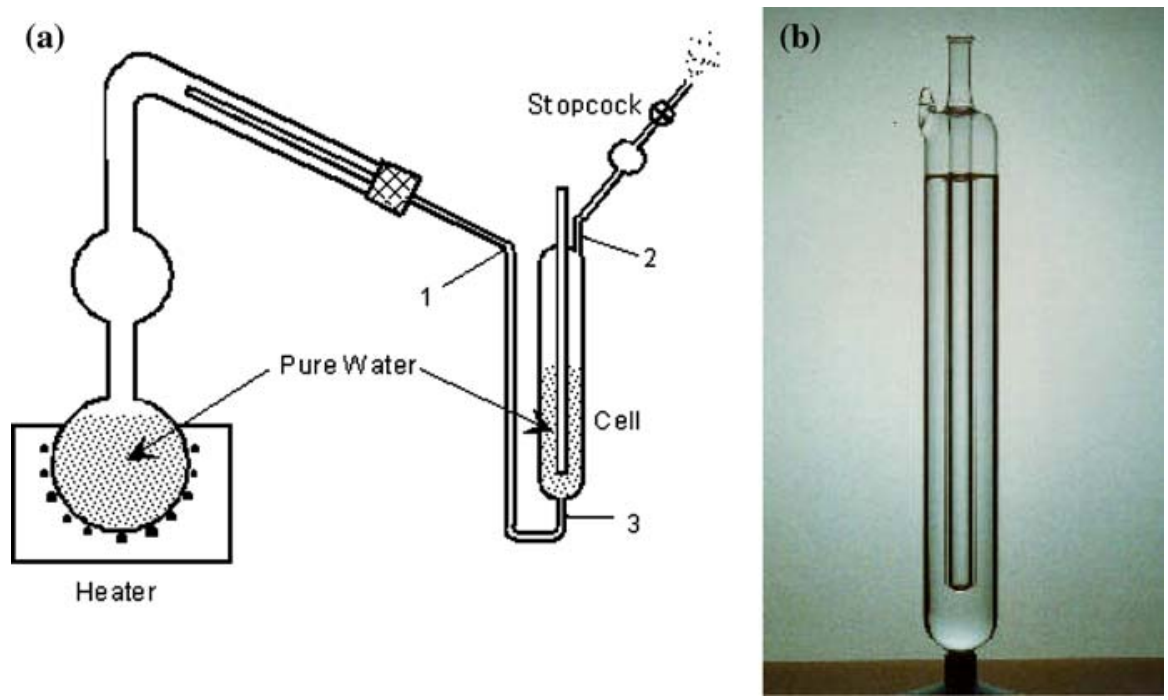

Fig. 1 Photographs: (a) sealing process for the TPW cell and (b) KRISS TPW cell

were selected from the TPW cells prepared in January 2002, and are referred to as KRISS-2002-Jan. Figure 1b is a photograph of the completed TPW cell. Each water ampoule has a capacity of $20 \mathrm{ml}$ and was manufactured using water from the sealed Pyrex tube remaining from the process of TPW cell manufacture. Before filling the ampoule with water, the ampoule was cleaned in an ultrasonic bath using the same acid cleaning solution as used in the fabrication of the TPW cells. After cleaning with dilute acid and filtered water several times, the ampoules were baked in a dry oven, whose temperature was controlled at $120^{\circ} \mathrm{C}$, for 2 days. This process is necessary to completely eliminate water from the surface of the Pyrex ampoule. Clean ampoules were maintained in a dry oven at $50^{\circ} \mathrm{C}$ to prevent adsorption of water from the air. Twenty water ampoules were prepared from the water of the sealed Pyrex tubes obtained from manufacturing the KRISS reference TPW cell (KRISS-2002-Jan) and the TPW cell KRISS-2005-Jun.

\subsection{Isotopic Analysis of Water}

Isotopic analysis of the water in the KRISS TPW cells was performed by three laboratories (1. GG Hatch Isotope Labs, University of Ottawa, Canada; 2. Korea Basic Science Institute (KBSI), Korea; 3. Shoko Company, Sugiti Laboratory, SI Research Center, Japan) to improve the reliability of the analysis results. The water ampoules were delivered to the GG Hatch Isotope Labs and the Shoko Company by airmail and hand-carried to the Korea Basic Science Institute. Each laboratory analyzed three ampoules of water from a TPW cell, and $\delta \mathrm{D}$ and $\delta^{18} \mathrm{O}$ isotopic compositions were measured by isotope ratio mass spectrometers. 


\section{Results}

\subsection{Isotopic Analysis of Water}

Table 1 shows the analysis results for the isotopic composition of water obtained by the three laboratories. The $\delta^{18} \mathrm{O}$ and $\delta \mathrm{D}$ values denote the deviation of the isotopic composition from the $\mathrm{V}-\mathrm{SMOW}$ values.

The analysis data of $\delta^{18} \mathrm{O}$ agreed within $\pm 0.12 \%$ and the $\delta \mathrm{D}$ data agreed within $\pm 1.18 \%$ among the three laboratories. The mean values of $\delta^{18} \mathrm{O}$ and $\delta \mathrm{D}$ were $(-9.41 \pm$ $0.03)$ and $-(62.17 \pm 1.63) \%$ for the KRISS-2002-Jan cell, and were $(-4.08 \pm 0.05)$ and $(-36.42 \pm 1.28) \%$ for the KRISS-2005-Jun cell.

\subsection{Correction of TPW Cell Temperature}

The isotopic composition of all naturally occurring surface water is sufficiently close to that of V-SMOW that the effect of the isotopes on the TPW can be specified by a linear function of the delta values,

$$
T_{\text {meas }}=T_{\mathrm{V}-\mathrm{SMOW}}+A_{\mathrm{D}} \delta \mathrm{D}+A_{17_{\mathrm{O}}} \delta^{17} \mathrm{O}+A_{18_{\mathrm{O}}} \delta^{18} \mathrm{O},
$$

where $T_{\mathrm{V}-\mathrm{SMOW}}$ is the same as $T_{90}(\mathrm{TPW})$ and the depression constants were found from Kiyosawa's data to be $A_{\mathrm{D}}=(628 \pm 6) \mu \mathrm{K}, A_{18_{0}}=(641 \pm 23) \mu \mathrm{K}$, and $A_{17_{\mathrm{O}}}=(57 \pm ?) \mu \mathrm{K}[8]$.

The concentration of ${ }^{17} \mathrm{O}$ is difficult to measure due to its low natural abundance; so its composition is not measured in this study. The deviation of the KRISS TPW temperature was determined using Eq. 1 and the measured data. Table 2 shows the deviations of the KRISS TPW temperatures from the defining TPW. The temperature of the KRISS-2002-Jan cell was lower by $45.07 \mu \mathrm{K}$ than the defining temperature, and the temperature of the KRISS-2005-Jun cell was lower by $25.49 \mu \mathrm{K}$ relative to the defining temperature. KRISS TPW cells fabricated in January 2002 were used as the transfer cell and reference cells in CCT-K7. The key comparison report shows that the KRISS TPW was higher by $(47 \pm 57) \mu \mathrm{K}(k=2)$ than the CCT-K7 KCRV. Considering the deviation of the KRISS TPW temperature as a result of isotope effects, the triple point of the KRISS-2002-Jan cell is $(92 \pm 57) \mu \mathrm{K}$ $(k=2)$ higher than the CCT-K7 KCRV. In the CCT-K7 report [3], six laboratories had knowledge of the isotopic composition of their TPW cells and two corrected their reference and transfer cells for the deviation from V-SMOW. The corrected TPW temperature of the six NMIs was +59 to $+117 \mu \mathrm{K}$ higher than the BIPM reference. Figure 2 shows the corrected TPW temperatures along with the KRISS TPW temperature. The KRISS TPW temperature compared indirectly with the corrected TPW temperatures of the NMIs agreed within the uncertainty, and the maximum difference between the KRISS TPW value and that of the other NMIs was $55 \mu \mathrm{K}$. 


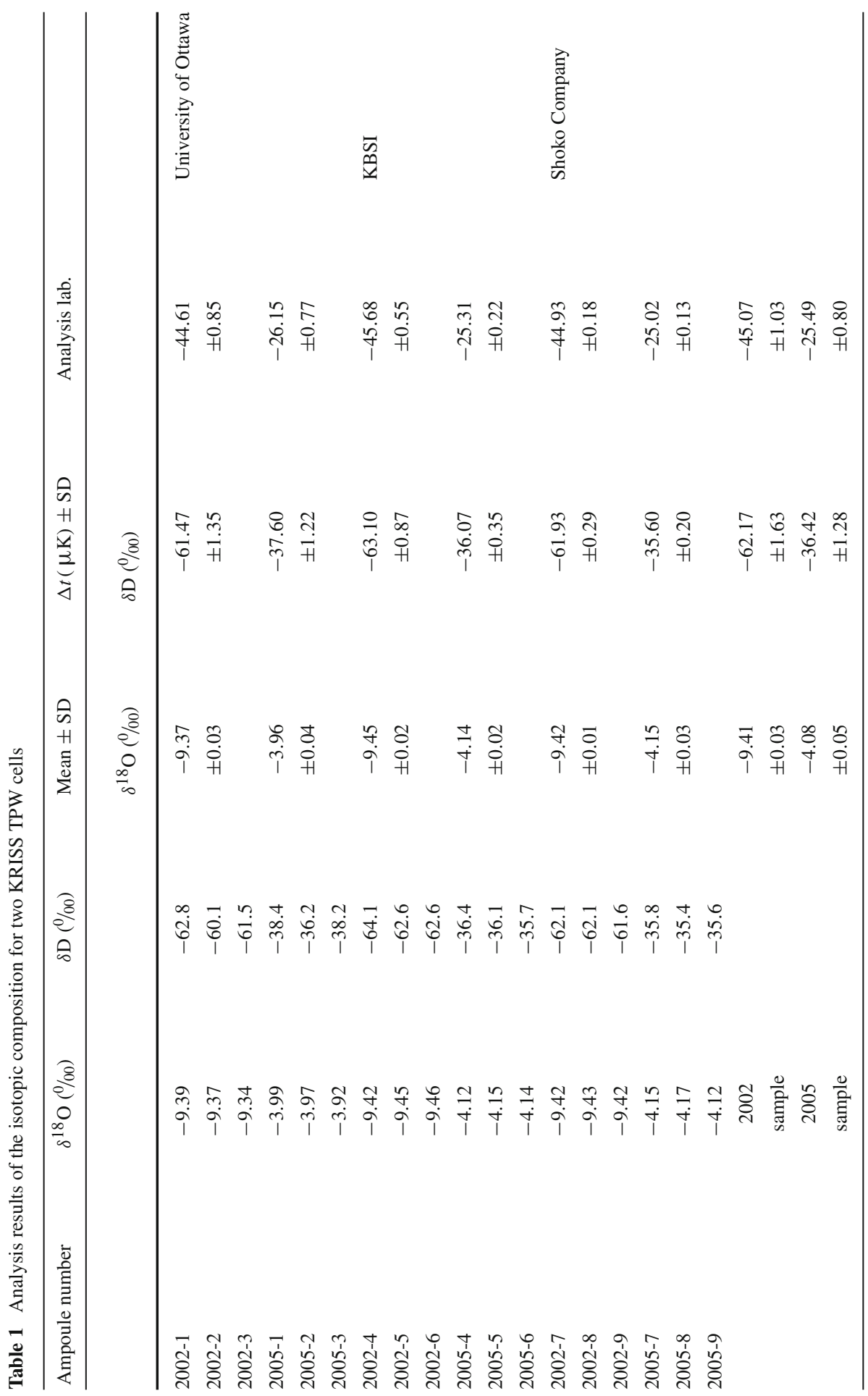


Table 2 Corrections to the realized temperatures based on the isotopic compositions of KRISS TPW cells

\begin{tabular}{lcc}
\hline KRISS TPW & KRISS-2002-Jan & KRISS-2005-June \\
\hline Deviation from the definition $(\mu \mathrm{K})$ & $+45.07 \pm 1.03$ & $+25.49 \pm 0.80$ \\
\hline
\end{tabular}

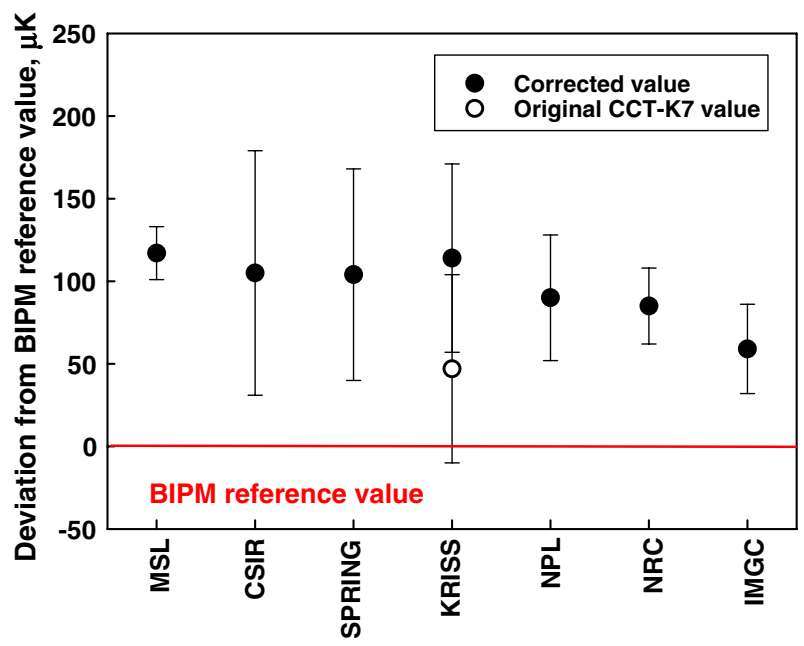

Fig. 2 TPW values for isotopic composition corrected NMIs used in CCT-K7

\section{Conclusions}

Isotopic analysis of the water in KRISS TPW cells was performed by three separate laboratories. The analysis data of $\delta^{18} \mathrm{O}$ agreed within $\pm 0.12^{\%} \%$, and the $\delta \mathrm{D}$ data agreed within $\pm 1.18 \%$ among the three laboratories. The mean values of $\delta^{18} \mathrm{O}$ and $\delta$ D were $-9.41 \%$ and $-62.17 \%$ for the KRISS-2002-Jan cell, and were $-4.08 \%$ and $-36.42 \%$ for the KRISS-2005-Jun cell. The deviation of the TPW temperature calculated using Kiyosawa's data was $-45.07 \mu \mathrm{K}$ for the KRISS-2002-Jan cell, and $-25.49 \mu \mathrm{K}$ for the KRISS-2005-Jun cell. The corrected temperature of the KRISS2002-Jan cell was $+92 \mu \mathrm{K}$ higher than CCT-K7 KCRV, but agreed with the corrected TPW temperatures of the NMIs that corrected their reference cell temperatures for the deviation from V-SMOW, the maximum difference being $55 \mu \mathrm{K}$.

Acknowledgment One of the authors gratefully acknowledges the technical assistance of Mr. C.H. Song of the Temperature/Optics Group at KRISS, during the fabrication of the TPW cells and the water ampoules.

Open Access This article is distributed under the terms of the Creative Commons Attribution Noncommercial License which permits any noncommercial use, distribution, and reproduction in any medium, provided the original author(s) and source are credited. 


\section{References}

1. H. Preston-Thomas, Metrologia 27, 3 (1990)

2. BIPM, Supplementary Information for the International Temperature Scale of 1990 (1990), http://www. bipm.org/en/publications/its-90_supplementary.html

3. M. Stock, S. Solve, D. del Campo, V. Chimenti, E. Méndez-Lango, H. Liedberg, P.P.M. Steur, P. Marcarino, R. Dematteis, E. Filipe, I. Lobo, K.H. Kang, K.S. Gam, Y.-G. Kim, E. Renaot, G. Bonnier, M. Valin, R. White, T.D. Dransfield, Y. Duan, Y. Xiaoke, G. Strouse, M. Ballico, D. Sukkar, M. Arai, A. Mans, M. de Groot, O. Kerkhof, R. Rusby, J. Gray, D. Head, K. Hill, E. Tegeler, U. Noatsch, S. Ďuriš, H.Y. Kho, S. Ugur, A. Pokhodun, S.F. Gerasimov, Final report on CCT-K7 key comparison of water triple point cells (2006), http://www.bipm.org/utils/common/pdf/final_reports/T/K7/CCT-K7.pdf

4. D.C. Ripple, K.S. Gam, Y. Hermier, K.D. Hill, R.L. Rusby, A.G. Steele, P.P.M. Steur, M. Stock, G.F. Strouse, D.R. White, Summary of Facts Relating to Isotopic Effects and the Triple Point of Water: Report of the Ad Hoc Task Group on the Triple Point of Water (CCT/05-07)

5. CCT, Recommendation T1(2005) to the CIPM, http://www.bipm.org/cc/CCT/Allowed/23/CCT_05_ 30_rev.pdf

6. CCT, Technical annex of the mise en pratique for the definition of the kelvin, http://www.bipm.org/ utils/en/pdf/MeP_K_Technical_Annex.pdf

7. R. Pello, R. Goebel, R. Köhler, Metrologia 34, 393 (1997)

8. K. Kiyosawa, J. Solution Chem. 20, 58 (1991) 